\title{
Hypothesis: Does the Apparent Protective Action of Green Valley's Drug GV971 Against Cognitive Decline Result from Antiviral Action Against Herpes Simplex Virus Type 1 in Brain?
}

\author{
Ruth F. Itzhaki* \\ Institute of Population Ageing, University of Oxford, Oxford, UK
}

\begin{abstract}
There has been much interest in the clinical trial of GV972 for treatment of Alzheimer's disease in that the data have indicated that the compound is protective against cognitive decline. This effect has been attributed to a remodelling of the gut microbiota. I suggest that the effect might be caused by an antiviral action of GV971 against herpes simplex virus type 1 in brain, which many studies have strongly implicated as having a major role in Alzheimer's disease. The antiviral action of GV971 is proposed on the basis that it is an acidic polysaccharide consisting of linear sodium oligomannurarate molecules of a range of sizes, derived from brown algae. Marine-derived polysaccharides are well known for possessing various bioactivities, including antiviral and antibacterial properties.
\end{abstract}

Keywords: Algae, antiviral, GV971, Herpes simplex virus type 1, marine polysaccharides, seaweed

Wang et al. have described the encouraging preliminary results of the GV971 clinical trial, which suggest that GV971 has a protective action against cognitive decline in Alzheimer's disease (AD) [1]. They propose that this might occur via alteration of the gut microbiota, reducing abnormal production of certain amino acids, and infiltration of immune cells to the brain, thereby reducing neuroinflammation. If confirmed, perhaps these results could be explained by an alternative, or an additional, mechanism: an antiviral effect. The common virus, herpes simplex virus type

${ }^{*}$ Correspondence to: Ruth F. Itzhaki, 66 Banbury Road, Oxford OX2 6PR, UK. Tel.: +44(01)865 250853; E-mail: ruth.itzhaki@ ageing.ox.ac.uk.
1 (HSV1), has been shown in well over 200 studies to play a major role in the development of $\mathrm{AD}$, following the discovery of the viral DNA in a high proportion of elderly brains [2]. More recently, HHV$6 \mathrm{~A}$ and HHV-7 have been suggested to be implicated in the disease [3-5]. The HSV1-AD concept postulates that the viral DNA resides latently in the elderly brain and reactivates periodically under conditions of stress, peripheral infection, etc. This leads to a productive infection with consequent damage, in $A P O E \& 4$ carriers in particular. On recurrent activation, the damage accumulates, leading eventually to the development of AD. Antiviral agents have therefore been suggested for treatment of the disease by slowing or stopping further viral damage. The studies 
described below substantiate the claim that antiviral action (and possibly antibacterial too) might account for the promising results of GV971 treatment.

GV971 is derived from brown algae and consists of polysaccharides-linear sodium oligomannurarate molecules_of a range of sizes. Marine-derived polysaccharides have been shown to have a variety of bioactivities [6], including antiviral effects [7], and also anti-bacterial effects, namely, inhibition of colonisation by oral bacteria such as $P$. gingivalis [8], which, like spirochetes and Chlamydia pneumoniae [9], have been implicated in AD. Thus, the usage of these polysaccharides for treatment of $\mathrm{AD}$ might be doubly beneficial in reducing not only viral but also any bacterial damage.

The antiviral activities of the marine-derived polysaccharides are usually related to the specific sugar structure, molecular weights, and their degree of sulfation (which, in the case of GV971, is not stated and so presumably is zero). Another group of polysaccharides derived, like GV971, from brown algae are the sulfated fucans (also known as fucoidans). These products have long been used as food supplements because they are considered to be protective against a variety of illnesses. They have been shown to have both antiviral and virucidal activity [10], and another group of sulfated polysaccharides, from "red marine algae", has antiviral activity against HHV6 [11]. In the case of the fucans, the virucidal activity is believed to be caused by the formation of a stable virion-sulfated polysaccharide complex, so that glycoproteins on the viral envelope required for virus attachment to host cells are occupied by the sulfated polysaccharide, thereby inactivating the virus; the antiviral activity is thought to be caused by sulfated polysaccharides interacting with and competitively inhibiting binding sites on the cell surface used by the virus, thereby preventing initial attachment of the virus to the host cells and subsequent viral entry and viral DNA replication [10]. In relation to $A D$, sulfated fucans were found to be effective in reducing greatly the levels of amyloid- $\beta(\mathrm{A} \beta)$ and especially $\mathrm{AD}$-like tau (Ptau) that accumulate in cultured cells when infected with HSV1 [12]. A comparison of sulfated fucans derived from different brown algae showed that the activity of the fucan extracted from Undaria pinnatifida against the HSV1-induced production of $\mathrm{A} \beta$ and P-tau was particularly effective [12]. Further, when this fucan was added to infected cells together with the most commonly used anti-HSV antiviral agent, acyclovir, which interferes specifi- cally with viral DNA replication, the combined effect was synergistic-appreciably more effective than either agent alone in decreasing levels of P-tau and $\mathrm{A} \beta$. Presumably, the sulfated fucan reduced the number of viruses entering the cells and, in the case of those viruses that did enter, acyclovir action in inhibiting the replication of their DNA inhibited also P-tau formation (as the latter, though not $A \beta$, depends on HSV1 DNA synthesis [13]); subsequently, the fucan, as well as acyclovir, would reduce $A \beta$ too by preventing the spread of any new viruses formed.

If GV971 is shown to have specific anti-HSV1 and HHV6 activity, there would be a strong case for treating $\mathrm{AD}$ patients with a combination of valacyclovir, the biodrug of acyclovir, and either a non-sulfated polysaccharide such as GV971, or else the sulfated fucan derived from Undaria pinnatifida, whichever has the greater anti-viral action against HSV1. Hopefully, Green Valley will encourage investigations to be made on GV 971 to find if it (and its sulfated product) does indeed have antiviral activity, as well as the proposed gut microbiome action.

\section{ACKNOWLEDGMENTS}

I thank Kristin Loomis for her help and advice.

The author's disclosure is available online (https:// www.j-alz.com/manuscript-disclosures/20-0210r1).

\section{REFERENCES}

[1] Wang X, Sun G, Feng T, Zhang J, Huang X, Wang T, Xie Z, Chu X, Yang J, Wang H, Chang S, Gong Y, Ruan L, Zhang G, Yan S, Lian W, Du C, Yang D, Zhang Q, Lin F, Liu J, Zhang H, Ge C, Xiao S, Ding J Geng M (2019) Sodium oligomannate therapeutically remodels gut microbiota and suppresses gut bacterial amino acids-shaped neuroinflammation to inhibit Alzheimer's disease progression. Cell Res 29, 787-803.

[2] Itzhaki RF (2018) Corroboration of a major role for herpes simplex virus type 1 in Alzheimer's disease. Front Aging Neurosci 10, 324.

[3] Lin WR, Wozniak MA, Cooper RJ, Wilcock GK, Itzhaki RF (2002) Herpesviruses in brain and Alzheimer's disease. J Pathol 197, 395-402.

[4] Readhead B, Haure-Mirande JV, Funk CC, Richards MA, Shannon P, Haroutunian V, Sano M, Liang WS, Beckmann ND, Price ND, Reiman EM, Schadt EE, Ehrlich ME, Gandy S, Dudley JT (2018) Multiscale analysis of independent Alzheimer's cohorts finds disruption of molecular, genetic, and clinical networks by human Herpesvirus. Neuron 99, 64-82.e7.

[5] Eimer WA, Vijaya Kumar DK, Navalpur Shanmugam NK, Rodriguez AS, Mitchell T, Washicosky KJ, György B, Breakefield XO, Tanzi RE, Moir RD (2018) Alzheimer's disease-associated $\beta$-amyloid is rapidly seeded 
by Herpesviridae to protect against brain infection. Neuron 99, 56-63.e3.

[6] Barzkar N, Tamadoni Jahromi S, Poorsaheli HB, Vianello F (2019) Metabolites from marine microorganisms, micro, and macroalgae: Immense scope for pharmacology. Mar Drugs 17, 464.

[7] Wang W, Wang SX, Guan HS (2012) The antiviral activities and mechanisms of marine polysaccharides: An overview. Mar Drugs 10, 2795-2816.

[8] Saeki Y, Kato T, Okuda K (1996) Inhibitory effects of funoran on the adherence and colonization of oral bacteria. Bull Tokyo Dent Coll 37, 77-92.

[9] Fülöp T, Itzhaki RF, Balin BJ, Miklossy J, Barron, AE (2018) Role of microbes in the development of Alzheimer's disease: State of the art - An International Symposium Presented at the 2017 IAGG Congress in San Francisco. Front Genet 9, 362.
[10] Harden EA, Falshaw R, Carnachan SM, Kern ER, Prichard MN (2009) Virucidal activity of polysaccharide extracts from four algal species against herpes simplex virus. Antiviral Res 83, 282-289.

[11] Naesens L, Bonnafous P, Agut H, De Clercq E (2006) Antiviral activity of diverse classes of broad-acting agents and natural compounds in HHV-6-infected lymphoblasts. $J$ Clin Virol 37 Suppl 1, S69-75.

[12] Wozniak M, Bell T, Dénes Á, Falshaw R, Itzhaki RF (2015) Anti-HSV1 activity of brown algal polysaccharides and possible relevance to the treatment of Alzheimer's disease. Int J Biol Macromol 74, 530-540.

[13] Wozniak MA, Frost AL, Preston CM, Itzhaki RF (2011) Antivirals reduce the formation of key Alzheimer's disease molecules in cell cultures acutely infected with herpes simplex virus type 1. PLoS One 6, e25152. 